\title{
PERCEPÇÃO SOBRE A ATITUDE INTERDISCIPLINAR DOS PROFESSORES NO CURSO DE CIÊNCIAS CONTÁBEIS: UM ESTUDO NAS UNIVERSIDADES NORTE RIO-GRANDENSES
}

\section{PERCEPTION ON THE ATTITUDE OF TEACHERS INTERDISCIPLINARY COURSE OF SCIENCES ACCOUNTING: A STUDY IN NORTE RIO-GRANDENSE}

\author{
VALDÉRIO FREIRE DE MORAES JÚNIOR \\ Mestre pela Universidade Federal do Rio Grande do Norte \\ Professor Assistente I do Departamento de Finanças e Contabilidade da \\ UFPB Universidade Federal da Paraíba - Paraíba / PB, Brasil \\ ANEIDE OLIVEIRA ARAUJO E-mail: valderio@ufrnet.br \\ Doutora em Ciências Contábeis pela Universidade de São Paulo \\ Professora Adjunta do Departamento de Contabilidade da Universidade \\ Federal do Rio Grande do Norte -UFRN \\ Natal/RN, Brasil \\ E-mail: aneide@ufrnet.br \\ MARIA INÊZ OLIVEIRA ARAUJO \\ Doutora em Educação pela Universidade de São Paulo \\ Professora Adj unta do Departamento de Educação da \\ Universidade Federal de Sergipe -UFS \\ Sao Cristovao / SE, Brasil \\ E-mail: inez@ufs.br

\section{RESUMO}

A interdisciplinaridade é responsável por um movimento que redimensiona a teoria das ciências, revisando os hábitos de pesquisa, constituindo em um meio de defesa para caminhos novos na área educacional. Para tanto, as ciências se apóiam na interdisciplinaridade para superar a fragmentação do ensino causada pelo desmembramento entre as disciplinas, como também nas atitudes interdisciplinares com relação ao professor do ensino superior. A presente pesquisa teve como objetivo identificar, nas universidades do Rio Grande do Norte, a percepção sobre a atitude interdisciplinar dos professores do curso de contabilidade. A metodologia utilizada compreende a análise de conteúdo das respostas obtidas, a partir da aplacação de questionário (perguntas abertas e fechadas). A amostra foi composta por 65 docentes de Contabilidade, que atuaram em 2008. Constatou-se que os professores das universidades do norte rio-grandenses demonstraramse atitude interdisciplinar de forma parcial, baseado nos seguintes elementos respondidos: $38,85 \%$ focam há possibilidade de realização de trabalhos integrados com outros docentes; $80 \%$ afirmam que 0 curso deveria focar as demandas do mercado de trabalho; 47,69\% relatam a necessidade da inserção de novos conhecimentos no currículo do curso; 67,69\% optaram em ordenar as disciplinas, para definir as áreas priorizadas no curso e 33,85\% assinaram que somente a prática pode consolidação de conhecimentos adquiridos.

Palavras-chaves: Atitudes Interdisciplinares, professores universitários e Rio Grande do Norte.

\section{ABSTRACT}

The interdisciplinary is responsible for a movement that re-calculates the size of the theory of the sciences, revising the habits of inquiry, as it also constitutes a means of defense for new ways in the education area. To do so, the literature is supported by interdisciplinary to surpass the fragmentation of teaching caused by the dismemberment among the subjects, and in the interdisciplinary attitudes regarding the teacher of Accounting Sciences. The present inquiry has as an objective to identify, in the universities of the State of Rio Grande do Norte, in Brazil, the perception on the interdisciplinary attitude of the professors in the course of Accounting Sciences. The used methodology takes a questionnaire with open and multiple choice questions, so that through the analysis of its content one manage to reach the terms most quoted by the respondent. The work of field had been carried out with 65 teachers of Accountancy of the universities of Rio Grande do Norte, who acted effectively in the second semester of the year of 2008, through answering the questionnaire, working in three distinct areas: financial covering $34.14 \%$ of the population, management with $45.12 \%$ and audit with $26.15 \%$. It is possible to affirm that Rio Grande do Norte's university professors have an interdisciplinary attitude in a partial form, based on the following answered elements: $38.85 \%$ commented that there are opportunities for achievement with other teachers integrated job, $80 \%$ said the course should be specific to meet the labor market, $47.69 \%$ emphasized the search for new knowledge to strengthen the grid; $67.69 \%$ chose the subjects in order to define the areas prioritized in the course and $33.85 \%$ chose to practice in real conditions for the consolidation of knowledge.

Key words: Attitudes interdisciplinary, university professors and Rio Grande do Norte. 


\section{INTRODUÇÃO}

Fazenda (2007a) diz que na educação é preciso uma postura que seja interdisciplinar, ou seja, uma forma de buscar, se envolver, ter compromisso e reciprocidade diante do ato dos docentes na integração de disciplinas do currículo escolar. É uma relação de mutualidade, um regime que oferece uma co-propriedade, possibilitando um diálogo entre as partes interessadas. Ainda consoante a essa autora, a interdisciplinaridade é a responsável por um movimento que redimensiona a teoria das ciências, revisando os hábitos de pesquisa, como também constituindo em um meio de defesa para caminhos novos na área educacional. Nos países desenvolvidos, é um tema discutido de forma ampla, como também em países emergentes.

O docente, como agente principal de transformação na educação, busca formas metodológicas para enriquecer o conhecimento dos fatos. Entretanto, segundo Marcovitch (1998, apud Andrade, 2002), o próprio professor oferece condições para que o aluno consiga construir o conhecimento. A correta prática da interdisciplinaridade consegue fazer com que o receptor tenha uma visão científica mais consistente, evidenciando a colaboração entre as disciplinas, mesmo aquelas consideradas heterogêneas. Esse método consegue integrar dois ou mais componentes curriculares contribuindo para construção do conhecimento. Além disso, é um meio para relacionar conceitos interligados que, por alguma razão, se desvincularam e se concentraram em áreas mais específicas.

Segundo Carvalho (2005), a formação do professor está apoiada por uma dimensão dialética, ou seja, como surge o conhecimento, a partir da aprendizagem, produzindo um diálogo interdisciplinar entre as variadas ciências.

Para ser professor, segundo Vasconcel os (1996, p. 10), o ideal seria ter três capacidades desenvolvidas de forma igual: "a do bom transmissor de conhecimentos; a do bom crítico das relações socioculturais da sociedade que o cerca e do momento histórico no qual vive; e a do bom pesquisador".

No Brasil, nem todos os docentes possuem essas três habilidades, geralmente adquirem uma e, no máximo, desenvolvem dois requisitos. Essa busca por um professor que seja apropriado ao perfil de docente é igual à procura do profissional que tenha uma boa formação, mas que acima de tudo seja propenso ao aprendizado profissional.

Santomé (1998) salienta que em um modelo disciplinar, cada professor preocupa-se apenas com sua matéria, considerando-a sempre a mais importante e forçando o conjunto de estudantes a interessar-se só por ela, podendo recorrer à desvalorização de outras que considerar rivais. Esse modelo é resultado de uma fragmentação de ensino que ocorreu em todas as áreas, não somente na área contábil.

Por muitos anos, o curso superior em Contabilidade que começou em 1945, no Brasil, teve como foco o conhecimento técnico voltado para escrituração dos livros contábeis. Anos depois, o profissional dessa área tornou-se necessário a partir da expansão do mercado de capitais no Brasil, com a obrigatoriedade das demonstrações financeiras e do parecer de um auditor independente possuidor do título de Bacharel em Ciências Contábeis (PASSOS, 2004). Contudo, ainda conforme Passos (2004), foi a partir do ano de 1951 que os concluintes puderam receber o título de Bacharel. Em 1968 veio outro passo importante com a reformulação do ensino universitário: a departamentalização e a matrícula por disciplina.

A reforma do currículo no curso de Ciências Contábeis ocorreu por intermédio da Resolução n. 03/ 92 do Conselho Federal de Educação através da criação do currículo mínimo, exaltando uma qualificação melhor aos profissionais da área, com a inclusão de disciplinas como Monografia e Trabalho de Conclusão de Curso. Pode-se dizer que um ponto relevante desse curso de graduação é o currículo, pois quando há uma relação positiva entre as grades 
e os pré-requisitos do curso escolhido pelo aluno, principalmente na área de negócios, como Contabilidade, os professores sugerem que essa relação seja relevante para formação profissional (WATSON et al., 2005).

Diante dessas circunstâncias, o problema dessa pesquisa é: qual é a percepção sobre a atitude interdisciplinar tomada pelos docentes no curso de graduação de Ciências Contábeis nas Universidades do Estado do Rio Grande do Norte? O objetivo é identificar, nas universidades do Rio Grande do Norte, a percepção sobre a atitude interdisciplinar dos docentes no curso de Ciências Contábeis

Por intermédio da observação direta extensiva, foi elaborado um questionário com perguntas abertas para solucionar ao problema de pesquisa sobre a atitude interdisciplinar dos docentes do curso de Ciências Contábeis. Já análise de conteúdo foi a técnica usada para identificar as palavras utilizadas pela população pesquisada. Assim sendo, esse artigo está dividido nas seguintes partes: introdução, referencial teórico, metodologia e análise dos resultados.

\section{REFERENCIAL TEÓRICO}

A presente seção discute os seguintes pontos relacionados ao tema pesquisado: fragmentação do ensino, disciplina e disciplinariedade, interdisciplinaridade, atitudes interdisciplinares na docência e a interdisciplinaridade no curso de Ciências Contábeis. 0 trabalho de Passos (2004) é considerado o pioneiro sobre o tema interdisciplinaridade na Contabilidade, destacando a departamentalização nas universidades que teve como conseqüência a fragmentação do ensino nas mais diversas áreas. Seguindo a linha dessa pesquisa, outros artigos foram feitos e apresentados em congressos brasileiros, alguns deles constam na seção 2.5 desse artigo.

Com referência a fragmentação, o professor de contabilidade tem focado a transmissão dos conhecimentos ao dar importância ao tecnicismo associado aos conteúdos mecanicistas, formando o profissional dentro dos padrões da racionalidade técnica. Porém, o docente dessa área precisa ser um profissional rico em saberes, capaz de intervir no momento devido e trabalhar com práticas pedagógicas com caráter inovador permitindo a apropriação do seu trabalho, através da reflexão de suas ações (LAFFIN, 2005).

\subsection{FRAGMENTAÇÃO DO ENSINO}

Conforme Garcia (2006), as escolas têm investido na formação de docentes e a interdisciplinaridade atualmente faz parte do vocabulário desses profissionais, portanto os professores já poderiam estar mais preparados perante a existência da fragmentação. 0 autor citado elenca perguntas para os quais os estudiosos da interdisciplinaridade procuram respostas, enquanto a fragmentação continua fazendo adeptos e sendo praticada: 0 que falta ainda para superá-la? Há necessidade de mais teorias? Até que ponto a formação dos professores precisa avançar? Existe um quadro atual de total acomodação? A interdisciplinaridade é algo complexo para ser exercida?

Ao analisar os questionamentos elaborados sobre a tendência à fragmentação, ou seja, as atitudes necessárias para promover a superação dessa realidade no ensino, Garcia (2006) observou cinco pontos: primeiro o que falta ainda ou que precisa ser feito no ensino para não fazer da fragmentação uma constante na sala de aula; o segundo referente à necessidade de mais teorias, no intuito de obter uma literatura sobre o tema bem vasto, 
principalmente em língua estrangeira, para dar um maior respaldo aos estudos.

O terceiro ponto sobre formação de docentes trata de uma questão árida, pois não se sabe como é exercida essa prática no cotidiano, se eles seguem os teóricos ou suas próprias intuições, existindo o que o autor acima citado chama de invisibilidade. Já o quarto referese à acomodação por parte dos professores, quando é aceita uma situação confortável e não mutável. Por último, a interdisciplinaridade está além de ser algo complexo que não pode ser exercido, pois é no próprio ambiente de ensino que ela cria práticas, que podem ajudar a inventar a interdisciplinaridade.

Santomé (1998) afirma que recortar cada problema em partes para haver uma melhor compreensão das epistemologias racionalistas e empiristas acaba causando uma fragmentação no saber, fomentando uma quantidade maior de disciplinas e ciências, de alguma forma existe, e é uma tendência à unidade do saber.

Essa fragmentação no ambiente de ensino da contabilidade se manifesta a partir do momento que os docentes elegem suas disciplinas mais rel evantes que as demais, considerando que aquele conhecimento é específico e totalmente independente das outras. Estudiosos como Santomé (1998) reconhecem esse problema como "disciplinariedade cruzada".

Ao mesmo tempo, torna-se contraditória essa posição, pelo fato de haver uma cobrança do que foi aprendido anteriormente. De tal forma, o docente se vê em conflito por algumas vezes exigir do aluno o mínimo de embasamento necessário para dar andamento a sua disciplina. Portanto, um ponto relevante apresentado por Passos (2004), acerca da disciplinarização, é que as teses e dissertações em Contabilidade no Brasil (período de 1962 a 1999) não têm características interdisciplinares; os temas teóricos abordados são: Contabilidade Gerencial, Contabilidade Financeira e Auditoria, percebendo leve aproximação da teoria com a prática.

O profissional contábil necessita de conhecimentos como psicologia, sociologia, filosofia, direito, administração e economia, por exemplos, para que ele possa enxergar outras áreas das ciências humanas (no caso de psicologia, sociologia e filosofia), como também das ciências sociais aplicadas, da qual a contabilidade faz parte (no caso de direito, administração e economia). Esses conhecimentos considerados obrigatórios ou complementares, dependendo da visão da Instituição, são vistos como base ideal para o profissional exercer suas habilidades de forma mais segura e eficaz, pois a contabilidade é uma ciência social aplicada que procura trabalhar sempre interligada com outras áreas, requerendo competências próprias.

\subsection{DISCIPLINA E DISCIPLINARIDADE}

Uma disciplina é uma categoria de fenômenos, consoante Palmade (1979), que os tornam inteligíveise a partir deles fazem possíveis previsões e estabelecem correspondências. Já Berger (1972) considera esse termo como um conjunto específico de conhecimentos, pois possui características pertinentes a área de ensino, nos mecanismos, na formação, nos materiais e nos métodos.

O ensino trabal ha com disciplinaridade para obter um relacionamento das disciplinas entre si, integrar áreas que até então eram vistas como distantes para possibilitar uma compreensão de tudo que se é discutido na atualidade e haver a transformação da educação quando ocorre interação entre as matérias.

Esse termo seria uma espécie de exploração científica, especializada em um domínio homogêneo e determinado, que consiste em produzir conhecimentos novos que vão substituir os antigos. A atividade disciplinar pode conduzir tanto a uma formulação quanto 
a reformulação contínua dos conhecimentos sobre o domínio em questão (HECKHAUSEN, 1972).

Enquanto a disciplina pode ser considerada um termo mais abrangente e genérico, adentrando em outras áreas afins, a disciplinariedade localiza-se especificamente em um ambiente mais educacional, conforme a literatura estudada. Esses conceitos são básicos para o entendimento da interdisciplinaridade.

\subsection{INTERDISCIPLINARIDADE}

A interdisciplinaridade é uma linguagem universal, a maneira de evitar a fragmentação do conhecimento, a partir do momento que as disciplinas contribuem entre si e se unem para um fim específico: o fortalecimento da ciência.

No período de 7 a 12 de setembro de 1970, realizou-se um seminário na cidade francesa de Nice, com a participação de 21 representantes de países membros da OCDE (Organization de Cooperation et de Developpement Economique). Dentre os especialistas estavam: H. Heckhausen, J. Piaget, E. Jantsch, M. Boisot e A. Lichenerowicz, que tinham como objetivo deixar claro o conceito de interdisciplinaridade, por meio de uma correspondência terminológica, com níveis de relacionamento entre as disciplinas discutidos por cada um dos estudiosos citados anteriormente. Esse encontro resultou em uma publicação chamada L'interdisciplinarit: problemes d'enseignement et de recherche dans Universités, que foi elaborada com base na terminologia empregada por três participantes: H. Heckhausen (Alemanha), M. Boisot (França) e E. J antsch (Austrália), com base nos níveis de relacionamento entre as disciplinas. A teoria da interdisciplinaridade se faz presente no mundo acadêmico. Centros de referência como o Centro de Intervenção Educativa (Crie), no Canadá, presidido por Ives Lenoir; Cirid na França, presidido por M. Sachot; Julie Klein nos Estados Unidos; Gerald Fourez na Bélgica e no Brasil, no Grupo de Estudos e Pesquisas em Interdisciplinaridade - GEPI, da Pontifícia Universidade Católica de São Paulo - PUCSP. Todos esses pesquisadores com uma produção teórica estimada de quase cinco mil pesquisas consideradas relevantes no período de 30 anos.

Fazenda (2007b, p. 17), por chegar à conclusão da impossibilidade de construir uma única, absoluta e geral teoria, sugere fracionar o estudo sobre interdisciplinaridade para fins didáticos, no século passado, em três décadas: 1970 - em busca de uma explicitação filosófica, ou seja, uma construção epistemológica da interdisciplinaridade; 1980 - em busca de uma diretriz sociológica, parțindo para uma explicitação das contradições epistemológicas decorrentes dessa construção; e, 1990 - em busca de um projeto antropológico, no qual se tenta construir uma nova epistemologia, que seria própria da interdisciplinaridade.

Dessa maneira, pode-se concluir que nos anos 70 procurou-se definir o que seria interdisciplinaridade, até pelo fato de ser uma palavra difícil de ser pronunciada, como também decifrada e, por conseguinte, traduzida. No Brasil, a palavra traduzida é interdisciplinaridade (do inglês ou do francês) e interdisciplinariedade (do espanhol).

Já nos anos 80, o esforço empreendido identificou que os pressupostos de uma convencional epistemologia não estavam conduzindo a um avanço em se compreender as implicações teóricas do que seria interdisciplinaridade.

Por fim, nos anos 90, segundo Fazenda (2007b, p. 34), "o número de projetos educacionais que se intitulam interdisciplinares vem aumentando no Brasil, numa progressão geométrica, seja em instituições públicas ou privadas, em nível de escola ou de sistemas de ensino". Assim, a autora constatou que na condição de ciência, esse assunto, na educação, não está caracterizado no acerto, mas sim no erro, que permite exercer e vivenciar a interdisciplinaridade nas mais diferenciadas relações. 


\subsection{ATITUDES INTERDISCIPLINARES NA DOCÊNCIA}

Alguns autores ao estudarem interdisciplinaridade apresentam duas razões para adotar essa atitude no ensino, segundo Miranda e Miranda (2006). A primeira é a gl obalização, a partir da fusão das áreas afins; a segunda é superar a fragmentação do conhecimento, ou seja, a impressão que o discente tem de estudar algo distinto das demais áreas, como também do docente considerar a sua disciplina a mais importante, passando essa visão aos alunos.

A interdisciplinaridade sozinha não pode solucionar os problemas educacionais, porém ela contribui para amenizar essa situação, a partir de uma atitude que favoreça a mudança na postura pedagógica que procure incentivar a pesquisa, estimulando a iniciativa, a cooperação e a co-responsabilidade entre as disciplinas (VAIDEANU, 1987).

Para tanto, uma atitude que seja interdisciplinar evidencia primeiro um projeto que venha a ser aprovado e agregado ao currículo, através de uma proposta que supere uma visão fragmentada de ensino, tornando o conhecimento como fonte de uma visão global do mundo.

Essa autora sustenta a característica da atitude interdisciplinar como uma ousadia na busca da pesquisa, em transformar a insegurança do docente em um exercício focado no pensar e na construção interdisciplinar por meio da troca, do diálogo e aceitação do pensamento das pessoas envolvidas. Por sua vez, há autores que defendem a prática da interdisciplinaridade pelo docente de forma individualizada: cada educador ensinando sua disciplina em uma perspectiva de maneira interdisciplinar.

No entanto, Carlos (2006) afirma que é uma prática quase impossível, pois é um processo que vai além do plano epistemológico, teórico, metodológico e didático, gerando a possibilidade do encontro, da partilha, da cooperação e do diálogo, que sugere uma ação conjunta dos professores.

A capacitação docente envolve um trabalho interdisciplinar, superando a fragmentação do ensino; a compreensão da aprendizagem do aluno, de forma gradativa; o diálogo em sala de aula, para proporcionar uma abertura democrática; entendimento do ambiente social, começando por um processo social e, por fim, a troca de experiências entre disciplinas, mesmo faltando domínio particularmente do que está sendo lecionado.

0 professor bem-sucedido e interdisciplinar tem um comprometimento com seus alunos que vai além do dever de cumprir seu horário semanal, não está satisfeito plenamente com seu trabalho, buscando algo novo quando ousa nas novas técnicas e na realização de técnicas não convencionais.

Garcia (2006), na sua pesquisa realizada no período entre 1999 e 2001 com um grupo de professores que participaram de cursos de formação e atuantes na rede pública de ensino, nos Estados do Paraná e de Santa Catarina, descreveu "o que é um professor interdisciplinar".

A interdisciplinaridade surge como uma condição necessária para reconciliação epistemológica, de tal forma que a formação do professor absorva uma consciência crítica no intuito da educação não se torne um instrumento de reprodução do sistema, mas sim desperte o senso crítico dos discentes, que venha proporcionar na educação uma ruptura não somente educacional, mas também na sociedade (NOGUEIRA, 1996).

Silva (2006) considera uma sala de aula interdisciplinar um lugar de encontro e parceira onde há interdisciplinaridade. Existem ordem e rigor de uma forma diferenciada, ou seja, não como punição; a autoridade é conquistada pelo docente; obrigações não existem, mas sim 
satisfações; a humildade substitui a arrogância; há cooperação no lugar da solidão; o grupo heterogêneo deixa de existir em prol do homogêneo, enfim, a produção do conhecimento ganha espaço no lugar da simples reprodução de idéias. Haas (1996) ressalta que a atuação docente está vinculada ao espaço da sala de aula, elaborando assim o que pode ser chamado de docência interdisciplinar, através da construção de novas ações pedagógicas.

\subsection{CONTRIBUICCÕES PARA O ESTUDO DA INTERDISCIPLINARIDADE NO ENSINO DE CONTABILIDADE}

A história da Contabilidade, segundo Walker (2005), revela a importância do vínculo entre as disciplinas, demonstrando que os artigos apresentados em Conferênciasinternacionais são baseados em perspectivas interdisciplinares. Esse quadro celebra a existência do estudo interdisciplinar nas pesquisas feitas, comprovada pela história contábil, sendo uma realidade e não somente promessa.

Roslender e Dillard (2003) propõem um projeto contemporâneo, de forma que haja uma coesão da teoria com a prática contábil, por meio do trabal ho interdisciplinar baseado na contabilidade social, tendo como principais pontos: questões de direitos humanos, dignidade humana e a condição humana como preocupação central.

No Brasil, o MEC, através do Parecer CNE/CES 776/97, emitiu uma orientação geral para as diretrizes curriculares dos cursos de graduação, incentivando uma formação sólida para que os egressos superem os desafios no exercício profissional como também na produção do conhecimento e venham a ter várias habilitações diferenciadas em um programa de curso, para expandir suas grades curriculares.

Já o parágrafo $1^{\circ}$, do art. $2^{\circ}$ Resolução 10 , da Resolução do CNE/CES, $n^{\circ} 10$ de 10/12/04, define que, o Projeto Pedagógico, além da clara concepção do curso de graduação em Ciências Contábeis, com suas peculiaridades, seu currículo pleno e operacional, abrangerá, sem prejuízo de outros, os seguintes elementos estruturais: formas de realização de interdisciplinaridade.

Observa-se que as formas de realização de interdisciplinaridade não são citadas ao longo da resolução, porém pode-se deduzir pela literatura por meio de autores como Zabala (2002, p. 33) que uma das principais formas seria "a interação entre duas ou mais disciplinas. Essas interações podem implicar transferências de leis de uma disciplina a outra, originando, em alguns casos, um novo corpo disciplinar, como, por exemplo, a bioquímica ou a psicologística".

Naárea das Ciências Sociais, comoadministraçãoecontabilidade, a interdisciplinaridade é um instrumento capaz de unir disciplinas com conteúdos específicos ou generalizados, como também se baseia em uma formação que atenda níveis básicos, intermediários e avançados, relacionando, de uma forma geral, a teoria com a prática. A interdisciplinaridade, no Curso de Ciências Contábeis, nem sempre é observada de forma explícita dentro da grade curricular e nas ementas do curso de forma explícita, principalmente na relação entre as disciplinas, no que diz respeito às pesquisas feitas sobre o assunto.

Sinatora et al (2005) fizeram uma análise das condições de oferta dos conteúdos de Sistemas de Informação nos cursos de Ciências Contábeis na cidade de São Paulo, identificando como pontos principais: integração entre os docentes do curso considerada baixa, pelo fato de haver apenas o cumprimento das aulas e pouca interdisciplinaridade, como resultado da interação quase inexistente entre os docentes.

Fragoso, Ribeiro Filho e Libonati (2006), relacionado ao processo de pesquisa dos doutores em Contabilidade no Brasil, analisaram o impacto da interdisciplinaridade quando se 
tem pelo menos uma formação seja em especialização, mestrado ou doutorado fora da área contábil. Esses pesquisadores verificaram que o perfil interdisciplinar torna-se consistente e atuante no processo de pesquisa (produção científica) ao longo do tempo.

Na pesquisa de Padoan e Clemente (2006), os autores afirmam que mesmo as Diretrizes Curriculares investindo em um ensino que valorize uma forma integradora na atuação do professor, uma disciplinaridade cruzada é mais observada quando se dá importância às disciplinas específicas do curso; já conhecimentos como economia, sociologia, entre outros são deixados na maioria das vezes de lado.

Por sua vez, Miranda e Miranda (2006) constataram na pesquisa realizada, a possibilidade de se ver alguns pontos de interdisciplinaridade, principalmente no final do curso, pois a partir daí cresce o número de disciplinas aplicáveis e mais relacionadas. Assim sendo, o professor é fundamental como facilitador desse processo, proporcionando conteúdos e técnicas atualizados, conforme mudanças ambientais internas e externas.

Pereira (2006), na sua dissertação de mestrado, discorre que diversas IES têm outras áreas do conhecimento distintas do campo da contabilidade, proporcionando uma forma de relacionamento entre as disciplinas, como a multidisciplinaridade. A pesquisa da autora revelou que há características interdisciplinares quando ocorre participação em grupos de pesquisa nas diversas áreas do conhecimento.

Outros pontos importantes na pesquisa de Pereira (2006) estão relacionados à atitude interdisciplinar dos professores, quando é sugerido que as IES tenham um corpo docente com áreas do conhecimento bem diferenciadas, o que não é visto na prática. Na opinião dos egressos, a interdisciplinaridade não foi um elemento que facilitou a entrada no mercado de trabalho.

Althoff e Domingues (2008) apresentaram em seu trabalho um resultado próximo ao de Passos (2004), ou seja, a existência, nos cursos de Ciências Contábeis da região estudada, de características multidisciplinares, pluridisciplinares e de disciplinaridade cruzada, ao fazer um levantamento junto a coordenadores de instituições de ensino superior localizadas na Mesoregião do Vale do Itajaí, situada no Estado de Santa Catarina. O resultado sugere que o cumprimento de cada disciplina é considerado mais relevante que obj etos ou conteúdos de estudo, identificando a existência da interdisciplinaridade.

Oliveira, Paiva e Melo (2008) descreveram e analisaram a contribuição do curso de Ciências Contábeis no que tange a prática pedagógica interdisciplinar, no que diz respeito à formação e desenvolvimento de competências profissionais nos alunos, a partir de uma pesquisa realizada em uma instituição de ensino superior privado do Estado de Minas Gerais, na percepção dos seus discentes. Os resultados encontrados mostram o quanto foi visível por parte do alunado a interdisciplinaridade mesmo que de forma tímida, em relação ao curso de forma geral.

Peleias et al (2008) fizeram um estudo com sete professores de Controladoria de quatro IES da cidade de São Paulo. Para tanto, uma relevante revisão da literatura sobre interdisciplinaridade foi feita, observando que ela é mais discutida do que vivenciada, apesar de ser respeitado o território dos ramos de conhecimento, trabalhando a superação das barreiras entre eles. Portanto, esses estudiosos verificaram que no curso de Ciências Contábeis, a interdisciplinaridade não está inserida de maneira ampla e clara, até mesmo nas práticas docentes, entretanto é percebida entre os atores a relevância dela em uma prática acadêmica para a formação discente. 


\section{METODOLOGIA}

O referencial teórico sobre a interdisciplinaridade, como também conceitos afins e suas características, tem como base principalmente livros especializados na área, artigos científicos, dissertações, sites da internet, para dar alicerce de maneira geral ao assunto explorado e respaldo para fortalecer os aspectos teóricos do trabalho. A partir da pesquisa bibliográfica, realizou-se uma pesquisa de campo, com o objetivo de identificar atitudes interdisciplinares tomadas pelos docentes no curso de Ciências Contábeis nas Universidades do Rio Grande do Norte, com uma população de 72 docentes, efetivamente atuando no segundo semestre de 2008 nas Universidades do RN, dos quais houve um retorno de 65 docentes.

Por meio da observação direta e extensiva, foi elaborado um questionário com perguntas abertas e fechadas que pretendem responder ao problema de pesquisa sobre a atitude interdisciplinar dos docentes do curso de Ciências Contábeis. Além dessas questões, foram elaborados quesitos de múltipla escolha para identificar o perfil dos respondentes. Trata-se, enfim, conforme a abordagem dada, de um estudo de natureza qualitativa realizado nas 3 universidades que possuem o curso de Ciências Contábeis no Estado do Rio Grande do Norte.

Quando da escolha da análise de conteúdo, segundo Bardin (1977), pode escolher a unidade de registro e de contexto. A unidade de registro é em geral seguida de algumas limitações, incluem características definidoras específicas, precisam estar adaptadas a esta ou aquela investigação e podem ser de tipos diferentes como: palavra, tema, personagem, item. Já a unidade de contexto é a parte mais abrangente do conteúdo a ser analisado, porém, consoante Puglisi e Franco (2005, p. 43) “é indispensável para a necessária análise e interpretação dos textos a serem decodificados [...] e, principalmente, para que se possa estabelecer a necessária diferenciação resultante dos conceitos de significado e sentido".

\section{ANÁLISE DOS RESULTADOS}

A análise dos resultados revela, após a coleta de 65 questionários, a realidade de uma população estimada em 72 docentes atuando efetivamente, no segundo semestre do ano de 2008, nas três universidades com Curso de Ciências Contábeis localizadas no Estado do Rio Grande do Norte - RN, Universidade Federal do Rio Grande do Norte - UFRN, Universidade do Estado do Rio Grande do Norte - UERN e Universidade Potiguar - UnP, com base no perfil dos respondentes e cinco questionamentos feitos.

\subsection{PERFIL DOS RESPONDENTES}

O questionário apresenta a caracterização dos respondentes com cinco categorias para quantificar. As cinco categorias são gênero (masculino ou feminino), tipo de instituição (pública e/ ou privada), o grau de instrução (graduado, especialista, mestrado ou doutorado) e a área de atuação (financeira, gerencial e auditoria/perícia). A amostra revela que dos 65 docentes, $65,61 \%$ são do sexo masculino e $34,39 \%$ do sexo feminino. Portanto, há predominância dos homens atuando na área acadêmica em relação às mulheres nesse ramo. Constata-se que $78,50 \%$ são de instituições públicas e $21,50 \%$ pertencem a instituição privada pesquisada. Uma observação importante é que $12,30 \%$ afirmaram ministrar aulas nos dois tipos de instituições, incluindo nesse caso outras faculdades particulares. Em relação ao grau de instrução dos respondentes, 18,46\% são graduados, 49,24\% especialistas, 30,76\% mestres 
e 1,54\% doutor. Quanto ao tempo de docência, apresenta a seguinte situação: $20 \%$ disseram que ensina a menos de 1 ano; 15,38\% afirmaram que leciona entre 1 a 3 anos; o mesmo percentual do item anterior, ou seja, 15,38\%estão atuando como docente entre 4 a 5 anos e por fim 49,24\% estão na área do ensino há mais de 5 anos.

Pode-se dizer que quase $50 \%$ dos professores estão na academia há mais tempo. Por sua vez, a área de atuação dos docentes foi dividida em três tipos distintos: financeira, abrangendo $34,14 \%$ da população; gerencial, com $45,12 \%$ e auditoria e perícia, com $26,15 \%$ Nessa opção, o respondente poderia marcar mais de uma alternativa.

\subsection{POSSIBILIDADE DE AVALIAÇÃO DE TRABALHOS INTEGRADOS COM OUTROS DOCENTES}

Essa questão pretende checar como funciona a possibilidade de avaliar trabalhos de forma integrada em conjunto com outros docentes durante o período que a disciplina está sendo ministrada. Portanto, com base nos 65 respondentes, chegou-se a seguinte freqüência relativa: $26,15 \%$ citaram suas "práticas interdisciplinares", $35 \%$ frisaram "sem possibilidades de realização" e 38,85\%comentaram "com possibilidades de realização".

As respostas fornecidas corroboram para constatar a existência de práticas interdisciplinares realizadas pelos docentes em $26,15 \%$ das respostas. Os professores acabam conversando com outros professores para analisar o conteúdo e vincular os trabalhos realizados, como também frisaram a utilidade de haver regras bem estabelecidas, para que possam existir trabalhos em grupo como uma forma de integração disciplinar.

Alguns docentes, 35\% responderam sem possibilidades de realização. Foi o caso do depoente 14 quando cita que a estrutura curricular e de infra-estrutura não permitem a aplicação integrada. J á outros professores, 38,85\% frisaram com possibilidades de realização a avaliação integrada, porém ainda não conseguiram realizá-la.

0 respondente 56 afirma tratar de uma possibilidade, porém exige a realização de um trabalho de equipe, definindo como funciona a integração. Para tanto, no momento da confecção do plano de ensino, deve ser observada essa realidade, evitando, inclusive que os alunos façam uma reclamação costumeira em sala de aula, quando observam ter visto alguns conteúdos em disciplinas ministradas anteriormente. Daí, o docente supracitado diz ser possível o entrelaçamento entre as matérias, não de forma repetitiva, mas fortalecendo principalmente as mais afins, como é o caso de análise de balanços e gerencial, por exemplo.

Por fim, dos termos citados pelos professores, fez-se uma relação com o perfil dos respondentes. Na sua maioria, os mestres da área gerencial, mais experientes, revelaram suas práticas sobre a integração dos trabalhos integrados com outros professores. Já os professores do campo gerencial e financeiro, incluindo o doutor e os especialistas, com uma relativa experiência, afirmaram não ter ainda feito, mas que existe uma possibilidade de realização. Por sua vez, os graduados e especialistas menos experientes foram mais taxativos e disseram não haver chance de concretizar esse tipo de integração.

\subsection{CURSO DE CIÊNCIAS CONTÁBEIS COM FOCO EM ÁREAS ESPECÍFICAS PARA ATENDER O MERCADO DE TRABALHO}

O ponto principal da pergunta é verificar se os professores concordam se o curso de Ciências Contábeis precisa focar áreas específicas para atender o mercado de trabalho ou ser um curso generalista, para absorver a demanda e prerrogativas que a carreira contábil 
pode oferecer.

O depoente 03 afirma que "há um dinamismo nas relações sociais, econômicas, comerciais, mercadológicas e tecnológicas. Assim sendo, a contabilidade precisa acompanhar essas tendências para poder atender os seus usuários". Dessa maneira, as pesquisas realizadas, principalmente as vinculadas às reais necessidades do usuário, são importantes para manter cada vez mais a ciência atualizada perante o mercado de trabalho.

Para "atender o mercado de trabalho", a grade curricular do Curso de Contabilidade, segundo a opinião dos docentes questionados, deve incluir disciplinas que sejam pertinentes à economia regional. Portanto, o projeto pedagógico precisa ser direcionado à região que o aluno faça parte. Para tanto, as especialidades do local servem como um guia para fortalecer a prática contábil.

Nesse contexto, o respondente 34 diz que "o mercado tem apresentado demandas cada vez mais especializadas, necessitando de enfoques como economia, direito, estatística, administração, entre outras". Corrobora com a mesma idéia o depoente 40, quando visualiza "a sinalização do mercado para as qualificações que serão exigidas no futuro; portanto, o curso deveria se antecipar e possibilitar uma formação mais adequada". Dessa forma, pode tornar o aprendizado dinâmico, entretanto existem áreas que necessitam de conhecimentos mais específicos, principalmente na Região Nordeste, como por exemplos: atividade imobiliária, agronegócio, petróleo e 0 sal, consoante respondente 56, são setores que geram renda e emprego nessa Região e que estão carentes de profissionais especializados.

Para o curso "não ser específico", 20\% dos respondentes afirmaram que a graduação é abrangente, enquanto a especialização precisa ser mais focada, sendo uma tarefa particular da pós-graduação ser mais específico. 0 depoente 35 acredita que "a grade curricular deve estar voltada para uma formação geral. 0 novo profissional deve focar sua área de atuação, a partir de uma especialização".

A relação do perfil dos respondentes com a questão mostra que os professores que acreditam no atendimento do mercado, através de áreas especificas, são na sua maioria especialistas e mestres do campo financeiro, com uma experiência em média de 1 a 3 anos. Já os docentes que optaram em afirmar ser o curso não específico são experientes, da área gerencial, incluindo os mestres e doutor.

\subsection{FORTALECIMENTO DA CIÊNCIA ATRAVÉS DA INTERAÇÃO ENTRE AS DISCIPLINAS CRIANDO NOVAS MATÉRIAS}

A questão investiga o fortalecimento da Ciência Contábil, por meio da interatividade que venha existir entre as disciplinas da grade curricular, tendo como finalidade a criação de uma disciplina nova e original. Nesse quesito, os professores deram ênfase à grade curricular que sofre mudanças de acordo com a necessidade da sociedade, além do mercado e a tecnologia que sofrem alterações, fazendo com que haja a busca por novos conhecimentos.

Com base nos 65 respondentes, chegou-se a seguinte freqüência relativa: 32,31\% enfatizaram a "mudança na grade", 47,69\% frisaram a "busca por novos conhecimentos" e 20,00\% afirmaram não ser interessante o fortalecimento da Ciência Contábil através da criação de novas disciplinas, por intermédio da interação entre as matérias já existentes.

A "mudança na grade" foi o termo citado por $32,31 \%$ dos docentes. 0 respondente 18 diz que "pela própria essência do curso, a grade tem que ser adaptada de acordo com a necessidade da sociedade".

Já a "busca por novos conhecimentos" está em 47,69\% das respostas. Os depoentes 
34, 35 e 38 observam que o conhecimento das disciplinas mais importantes para o mercado de trabalho podem favorecer para gerar uma disciplina nova, mais assimilada pelos alunos e fácil de ser aplicada. 0 respondente 53 enfatiza que uma ciência deve interagir com outras, para haver discussões e gerar conhecimentos na área econômica, principalmente; esse fato acontece quando ocorrem palestras de áreas distintas, abordando temas em comum, porém sob óticas diferentes.

Da amostra pesquisada, 20,00\% optaram em afirmar que "não é interessante" essa interação entre as disciplinas para que surja uma mais atual. Os professores que decidiram responder negativamente, não explicitaram o motivo por ter escolhido essa alternativa.

0 intuito da questão é observar a interação entre as disciplinas, com o objetivo de criar matérias novas. A relação desse quesito com o perfil do respondente, no que tange à mudança da grade, mostra um interesse maior por parte dos mestres e especialistas mais experientes da área financeira. Já os especialistas com uma experiência entre 1 a 3 anos, mais voltados à gerencial, buscam novos conhecimentos para aprimorar suas disciplinas. Por sua vez, na maioria mestres e doutor de todas as áreas acreditam não ser interessante para o curso a criação de novas disciplinas da forma proposta na pergunta supracitada.

\section{5 ÁREAS PRIORIZADAS PELO FUTURO CONTADOR PARA ATENDER O MERCADO DE TRABALHO}

0 quesito elenca, segundo a opinião dos docentes, as áreas priorizadas pelo futuro profissional da Contabilidade, de maneira que o egresso possa atender o mercado de trabalho. Dessa forma, foi solicitada a enumeração das áreas, considerando a de número 01 a mais importante.

Inicialmente, a ordem apresentada no questionário foi, do número 01 ao 09: Finanças, Auditoria, Direito, Economia, Contabilidade Governamental, Contabilidade Empresarial, Perícia, Outra(s) e Não existe prioridade. Conforme tabela 1, após aplicação do questionário, a seqüência ficou a seguinte: Contabilidade Empresarial, Finanças, Auditoria, Contabilidade Governamental, Perícia, Direito, Economia, Não existe prioridade e Outra(s).

Tabela 1 - Ordem das disciplinas após aplicação do questionário

\begin{tabular}{|c|c|}
\hline Ordem & Disciplinas \\
\hline 1 & Contabilidade empresarial \\
\hline 2 & Finanças \\
\hline 3 & Auditoria \\
\hline 4 & Contabilidade governamental \\
\hline 5 & Perícia \\
\hline 6 & Direito \\
\hline 7 & Economia \\
\hline 8 & Não existe prioridade \\
\hline 9 & Outra área \\
\hline
\end{tabular}

Fonte: Elaborado pelo autor (2009)

As outras disciplinas citadas foram: Gerencial, Contabilidade aplicada ao Turismo, Contabilidade Tributária, Estatística e Administração. As matérias mais mencionadas no questionário foram: Gerencial e Contabilidade Tributária, por quatro professores, cada uma e Administração, lembrada por 2 docentes. 
Dos participantes da pesquisa, 32,31\% disseram que no Curso de Ciências Contábeis, não existe prioridade entre as disciplinas, ou seja, todas são importantes, não havendo matéria que sobressaia em relação às ministradas pelos outros docentes. A literatura a respeito da interdisciplinaridade explica essa tendência em haver um entrelaçamento entre as disciplinas, para evitar o atual estágio da fragmentação no ensino, particularizando cada vez mais o conhecimento adquirido pelos discentes.

Já 67,69\% optaram em ordenar as disciplinas como forma de justificar as áreas priorizadas pelo contador, porém os professores foram quase unânimes em concordar que a classificação é meramente formal, não sendo uma realidade absoluta uma matéria se tornar superior à outra.

\subsection{CONSOLIDAÇÃO DOS CONHECIMENTOSADQUIRIDOS PELO ALUNO NACONCLUSÃO DO CURSO}

O intuito da questão 10 é constatar, consoante os professores questionados, as necessidades do aluno concluinte, para que os conhecimentos adquiridos sejam consolidados.

Tabela 2 - Ordem dos itens após aplicação do questionário

\begin{tabular}{|c|c|}
\hline Ordem & Itens \\
\hline 1 & Prática em condições reais \\
\hline 2 & Três itens juntos \\
\hline 3 & Dois itens juntos \\
\hline
\end{tabular}

Fonte: Elaborado pelo autor (2009)

A ordem apresentado no questionário dos itens necessários para a consolidação dos conhecimentos durante o curso de Contabilidade são: prática em condições reais, prática simulada e a monografia. Conforme tabela 2, após aplicação do questionário, os professores destacaram nessa seqüência: prática em condições reais nas entidades, os três itens juntos e dois itens assinalados, sendo que a maioria deu prioridade a prática simulada em laboratório e a monografia.

Os termos assinalados pelos docentes estão na tabela 13: 33,85\% marcaram "prática em condições reais", 32,31\% optaram pelos três itens juntos, 18,46\% responderam dois itens juntos, enquanto $9,23 \%$ e $6,15 \%$ escolheram, respectivamente, nessa ordem, apenas laboratório e somente monografia.

A "prática em condições reais", ou seja, nas entidades, surge em 33,85\%das respostas. 0 respondente 30 diz que "o aluno precisa vivenciar a contabilidade dentro de uma empresa, com suas documentações, com suas peculiaridades e vendo principalmente que, em alguma situação a teoria é diferente da prática". Por sua vez, o depoente 31 justifica sua escolha ao afirmar que "para os que pretendem entrar no mercado de trabalho como contador, necessita ter a parte prática ligada à teoria.

Os "três itens juntos", ou seja, prática em condições reais, prática simulada e monografia, foram assinalados por $32,31 \%$ dos professores. A justificativa do respondente 34 foi que para haver uma formação mais coerente do profissional contábil, há necessidade que haja um conjunto de informações teóricas e práticas, com as técnicas adquiridas, para alcançar uma formação plena, incluindo o cotidiano profissional e a pesquisa. Já o depoente 59 foi mais objetivo ao afirmar que "a prática nas entidades mostra ao aluno a situação real, no laboratório aprimora-se o conhecimento e a monografia faz com que estimule o aluno a 
fazer pesquisa".

"Dois itens juntos" foram escolhidos por $18,46 \%$ dos docentes. Nesse caso, a relação entre a prática simulada e a monografia acabou sendo mais mencionada pelos respondentes. 0 depoente 32 justifica sua escolha ao dizer que para saber como funciona a pratica não precisa estar nas entidades; o acompanhamento de um professor na prática simulada é importante, o que muitas vezes não acontece nas entidades; assim sendo, a monografia tem sua relevância, pois coloca o discente de frente à pesquisa.

"Apenas laboratório" foi citado por 9,23\% dos professores. 0 respondente 03 deu um depoimento mais contundente sobre sua escolha, ao dizer que, para o aluno de Contabilidade seria mais interessante a prática em condições reais, para haver uma intimidade com o mercado de trabalho; porém os discentes do curso não dispõem de horário vago para estagiar, pois muitos deles já exercem uma atividade profissional, portanto, a solução seria a prática simulada em laboratório; dessa forma, esse trabalho tem que ter como alicerce a teoria contábil, sendo do aluno cobrado não apenas como "fazer", mas sim explorar dele os conhecimentos obtidos durante o curso.

O item "apenas monografia" surge em 6,15\% das respostas dadas. Os professores preferiram responder que a monografia dispensa os demais itens, além de ser abrangente por absorver todos os requisitos para os futuros profissionais.

O relacionamento feito entre o perfil dos depoentes e o presente quesito demonstra professores unidos ao optar em "prática em condições reais" ou os "três itens juntos: prática real, simulada e monografia", que somados representam $66,16 \%$ da amostra. Esse resultado revela uma preocupação dos docentes das três áreas (financeira, gerencial e auditoria/ perícia), voltados ao mesmo ponto em comum, independente de titulação e de tempo de experiência, tipo de instituição e gênero (masculino ou feminino): que os conhecimentos adquiridos pelos discentes sejam consolidados por intermédio de atividades edificantes ao propenso egresso do Curso de Ciências Contábeis.

\subsection{RELAÇÃO ENTRE OS RESULTADOS E A TEORIA SOBRE A INTERDISCIPLINARIDADE}

A primeira questão indaga sobre a possibilidade de avaliação de trabalhos integrados com outros docentes. Os estudos feitos pela Interdisciplinary Studies (1990), no século $X X$, detectaram que de forma integradora, a interdisciplinaridade visa um equilíbrio entre amplitude, profundidade e síntese. A amplitude tem uma base larga de conhecimento e informação. Já a profundidade trabalha o requisito disciplinar, profissional e/ ou conhecimento da informação interdisciplinar na tarefa a ser colocada em prática, por último, a síntese que consolida o processo integrador. 0 resultado encontrado demonstra essa preocupação dos docentes, quando 38,85\% comentaram que há possibilidades de realização de trabalhos feitos em conjunto com outros docentes do curso.

Por sua vez, o segundo questionamento visa identificar se o curso de Ciências Contábeis deve ter como foco áreas específicas e assim atender o mercado de trabalho ou ser um curso generalista. Conforme os teóricos da educação, as escolas têm investido na formação de docentes e a interdisciplinaridade atualmente faz parte do vocabulário desses profissionais, portanto os professores já poderiam estar mais preparados perante a existência da fragmentação. Seguindo essa tendência, $80 \%$ dos respondentes afirmaram que o curso deve ser específico, confirmando mais uma vez uma situação prevista pelos educadores, no que diz respeito à fragmentação do ensino.

Já a terceira questão verifica como pode ocorrer o fortalecimento da Ciência Contábil, 
ao criar, na grade curricular, uma disciplina nova e original. Os educadores afirmam que a interação entre duas ou mais disciplinas pode originar um novo corpo disciplinar. Nas respostas fornecidas pelos docentes, foi observado que a busca por novos conhecimentos está em 47,69\% das respostas. Assim sendo, os respondentes enfatizaram que o curso deve priorizar novas áreas de conhecimento, para incluir na grade curricular disciplinas mais atualizadas.

0 quarto questionamento foi em relação às áreas priorizadas pelo futuro contador para atender o mercado de trabalho. No inicio da década de 70 , do século XX, os estudiosos em educação se reuniram para discutir o conceito de interdisciplinaridade, através de uma correspondência terminológica, para verificar os níveis de relacionamento entre as disciplinas. Nos resultados encontrados no presente trabalho, 32,31\% dos professores disseram que, no curso de Ciências Contábeis, não existe prioridade entre as disciplinas, porém a maioria preferiu elencar as disciplinas, elegendo contabilidade empresarial como sendo a mais importante matéria do curso.

Na quinta questão, sobre a consolidação dos conhecimentos adquiridos pelo aluno na conclusão do curso, a intenção foi checar as necessidades do discente, no momento do término do curso. A teoria da interdisciplinaridade diz que o aluno, em uma visão multidisciplinar, acaba tendo uma percepção sobre tudo que o curso pode proporcionar, para consolidar os conhecimentos adquiridos. Para tanto, 33,85\% dos respondentes admitem que a prática em condições reais, ou seja, a operacionalização das atividades contábeis dentro de uma entidade possibilita essa habilidade ao futuro contador.

\section{CONSIDERAÇÕES FINAIS}

O trabalho teve como alicerce as respostas fornecidas ao longo da pesquisa de campo realizada com sessenta e cinco docentes em uma população ativa de setenta e dois professores universitários. Diante do exposto, o problema da pesquisa é respondido com base nas respostas fornecidas, ou seja, se a atitude interdisciplinar dos professores das universidades do RN, no Curso de Ciências Contábeis, existe.

A interdisciplinaridade, por ser algo intencional, realizada de maneira consciente e objetiva, tem como ponto de partida um projeto, porém precisa antes de tudo ser dialogada, inter-relacionada e integrada. As implicações de se por em prática uma atitude que seja considerada interdisciplinar leva em questão que deve partir do próprio docente em oferecer condições para que o aluno consiga construir o conhecimento, para produzir o chamado efeito metadisciplinar, ou seja, o professor como peça-chave do processo educativo, quebrando barreiras entre as disciplinas, aproximando-se mais do discente.

Do perfil dos respondentes, constata-se, pelo trabalho realizado, que a maioria dos professores é do gênero masculino e docente de universidades públicas. A maior parte é formada por especialistas, com mais de 5 anos atuando na academia e da área gerencial e a partir dos dados tabulados, pode-se afirmar que os professores das universidades norte rio-grandenses tem uma atitude interdisciplinar de forma parcial, baseado nos seguintes elementos respondidos:

$38,85 \%$ comentaram que há possibilidades de realização, com outros docentes, de trabalhos integrados; $80 \%$ disseram que o curso deve ser específico, para atender o mercado de trabalho; $47,69 \%$ frisaram a busca por novos conhecimentos, para fortalecer a grade; $67,69 \%$ optaram em ordenar as disciplinas, para definir as áreas priorizadas no curso e $33,85 \%$ escolheram a prática em condições reais, para a consolidação de conhecimentos adquiridos.

A pesquisa apresenta uma relevante contribuição às IES que oferecem cursos de graduação em Ciências Contábeis, pelo fato da interdisciplinaridade ser um assunto discutido 
nas diretrizes curriculares tanto nas instituições públicas quanto privadas, principalmente nos projetos políticos pedagógicos. Tendo em vista a limitação desse trabalho, o número de instituições pesquisadas (três) não invalida os achados encontrados, ao considerar a análise dos dados coletados, por meio de uma pesquisa de campo, cujo referencial teórico pesquisado sobre a interdisciplinaridade está cada vez mais sendo aprimorado, com abordagens metodológicas aperfeiçoadas, as recomendações para futuras pesquisas são: a utilização de uma diferente técnica para coleta de dados, envolvimento dos professores de Contabilidade das universidades da Região Nordeste e uma comparação com as instituições de outras regiões brasileiras.

\section{REFERÊNCIAS}

ALTHOFF, Noemia Schroeder; DOMINGUES, Maria José Carvalho de Souza. Práticas interdisciplinares nos cursos de graduação em Ciências Contábeis: mito ou realidade. In: CONGRESSO DA ASSOCIAÇÃO NACIONAL DOS PROGRAMAS DE PÓS-GRADUAÇÃO EM CONTABILIDADE, 2, 2008, Salvador. Anais... Salvador: ANPCONT, 2008, p. 1-16.

ANDRADE, Cacilda Soares de. O Ensino de Contabilidade Introdutória nas Universidades Públicas do Brasil. 2002. 153f. Dissertação (Mestrado em Contabilidade) - Faculdade de Economia, Administração e Contabilidade. Universidade de São Paulo, São Paulo, 2002.

BARDIN, Laurence. Análise de conteúdo. Lisboa: Edições 70, Lda, 1977.

CARLOS, Jairo Gonçalves. Interdisciplinaridade: o que é isso? Disponível em: <www.unb.br/ ppgec/ dissertacoes/ proposicoes/ proposicao_jairocarlos. pdf>. Acesso em: 04 out. 2008.

CARVALHO, Ademar de Lima. Os caminhos perversos da educação: a luta pela apropriação do conhecimento no cotidiano da sala de aula. Cuiabá: Edufmt, 2005.

CONSELHO FEDERAL DE EDUCAÇÃO. RESOLUÇÃO N. 3, DE 5 DE OUTUBRO DE 1992. Fixa os mínimos de Conteúdos e duraçã̃o do curso de graduação em Ciências Contábeis. Disponível em:.<www.jusbrasil.com.br>. Acesso em: 20 fev. 2008.

CONSELHO NACIONAL DE EDUCAÇÃO - CÂMARA DE EDUCAÇÃO SUPERIOR - PARECER CNE/CES 776, DE 03 DE DEZEMBRO DE 1997 - Orientação para as diretrizes curriculares dos cursos de graduação. Disponível em: <www.mec.gov.br>. Acesso em: 18 jan. 2008.

CONSELHO NACIONAL DE EDUCAÇÃO - CÂMARA DE EDUCAÇÃO SUPERIOR - RESOLUÇÃO CNE/ CES 10, DE 16 DE DEZEMBRO DE 2004 - Diretrizes Curriculares Nacionais para o Curso de Graduação em Ciências Contábeis, bacharelado. Disponível em: <www.mec.gov.br>. Acesso em: 18 jan. 2008.

FAZENDA, Ivani C. A. (Org.). Didática e interdisciplinaridade. Campinas: Papirus, 2007a. Papirus, 2007b.

Ivani C. A. Interdisciplinaridade: história, teoria e pesquisa. 14a edição. Campinas:

FRAGOSO, Adriana Rodrigues; RIBEIRO FILHO, José Francisco; LIBONATI, Jerônymo José. Um estudo aplicado sobre o impacto da interdisciplinaridade no processo de pesquisa dos doutores em contabilidade no Brasil. Revista Universo Contábil. Blumenau, v. 2, 1, p. 103112, jan./ abr., 2006.

GARCIA, Joe. As práticas invisíveis da interdisciplinaridade. In: FAZENDA, Ivani. (Org.) Interdisciplinaridade na formação de professores: da teoria à prática. Canoas: ULBRA, 2006. 
HAAS, Célia Maria. A interdisciplinaridade na construção de um projeto de universidade: a paixão pela prática. 1996. Tese (Doutorado em Educação) - Pontifícia Universidade Católica PUC-SP, São Paulo, 1996.

HECKHAUSEN, Heinz. Discipline et interdisciplinarité. In: Ceri (Eds.) L'interdisciplinarité. Problèmes dénseignement et de recherche dans les Universités. Paris: UNESCO/OCDE, $p$. 71-86, 1972.

LAFFIN, Marcos. De contador a professor: a trajetória da docência no ensino superior da contabilidade. Florianópolis: Imprensa Universitária, 2005.

MIRANDA, Cláudio; MIRANDA, Raissa Álvares de Matos. Interdisciplinaridade e métodos de ensino no curso de contabilidade: um estudo no Nordeste Paulista. In: CONGRESSO USP DE CONTROLADORIA E CONTABILIDADE, 6, 2006, São Paulo. Anais... São Paulo: USP, 2006, v. 6, p. 1-15.

NOGUEIRA, Adriano (Org.). Contribuições da interdisciplinaridade: para a ciência, para a educação, para o trabalho sindical. 3.ed. Petrópolis: Vozes, 1996.

OLIVEIRA, Michelle Cristina de Souza Mendes; PAIVA, Kelly César Martins; MELO, Marlene Catarina de Oliveira Lopes. Formação de Competências Profissionais e Interdisciplinaridade no Curso de Ciências Contábeis: percepções dos discentes. In: ENCONTRO DA ANPAD, 32, 2008, Rio de Janeiro. Anais... Rio de Janeiro: ANPAD, 2008, v. 1. p. 1-16.

PADOAN, Fátima Aparecida da Cruz; CLEMENTE, Ademir. A interdisciplinaridade no ensino da Contabilidade: um estudo empírico da percepção dos docentes. In: CONGRESSO USP DE CONTROLADORIA E CONTABILIDADE, 6, 2006, São Paulo. Anais... São Paulo: USP, 2006, v. 6, p. 1-15.

PALMADE, Guy. Interdisciplinaridad e idelologias. Madrid: Narcea, 1979.

PASSOS, Ivan Carlin. A interdisciplinaridade no ensino e na pesquisa contábil: um estudo no município de São Paul o. 2004. 164f. Dissertação (Mestrado em Ciências Contábeis) - Faculdade de Economia, Administração e Contabilidade. Universidade de São Paulo, São Paulo, 2004.

PEREIRA, Ivone Vieira. Interdisciplinaridade no Ensino: a percepção dos egressos dos cursos de graduação em Ciências Contábeis. 2006. 123f. Dissertação (Mestrado em Ciências Contábeis). Universidade de Brasília, Brasília, 2006.

PELEIAS, Ivam Ricardo et al. Pesquisa sobre a percepção da interdisciplinaridade por professores de Controladoria em cursos de Ciências Contábeis na cidade de São Paulo. In: ENCONTRO DA ANPAD, 32, 2008, Rio de Janeiro. Anais... Rio de Janeiro, ANPAD, v. 1, p. 1-15, 2008.

PUGLISI, M. L.; FRANCO, B. Análise de conteúdo. 2.ed. Brasília: Líber Livro, 2005.

ROSLENDER, R.; DILLARD, Jesse. Reflections on the interdisciplinary perspectives on accounting research. Critical Perspectives on Accounting, 14, 3, p. 325-351, 2003.

SANTOMÉ, Jurjo Torres. Globalização e interdisciplinaridade: o currículo integrado. Porto Alegre: Artes Médicas, 1998.

SILVA, Maurina Passos Goulart. O. da. Interdisciplinaridade, literatura e linguagem: um encontro com a palavra. In: FAZENDA, Ivani. (Org.) Interdisciplinaridade na formação de professores: da teoria à prática. Canoas: ULBRA, 2006.

SINATORA, José Roberto Pereira et al. Construção e validação de uma escala de atitude para 
a avaliação do ensino de Sistemas de Informação nos cursos de Ciências Contábeis da cidade de São Paulo. Encontro Nacional dos Programas de Pós-Graduação em Administração, 29, Brasília. Anais... Rio de Janeiro: ANPAD, 2005, p. 1-15.

VASCONCELOS, Maria Lucia M. Carvalho. A formação do professor do terceiro grau. São Paulo: Pioneira, 1996.

VAIDEANU, George. Interdisciplinarity in education: a tentative synthesis. In: Quartely review of education; XVII, p. 489-501, 1987.

WALKER, S.P. Accounting in history. Accounting Historians Journal, v. 33, 2, p. 233-259, 2005.

WATSON, Stephanie F. et al. Accounting education literature review (2003-2005). Journal of Accounting Education. United States, 25, 2005.

ZABALA, Antoni. Enfoque globalizador e pensamento complexo: uma proposta para o currículo escolar. Porto Alegre: Artmed, 2002.

\section{ENDEREÇO DOS AUTORES:}

Universidade Federal da Paraíba, Centro de Ciências Sociais Aplicadas - Campus I, Departamento de Finanças e Contabilidade.

Cidade Universitária $\mathrm{s} / \mathrm{n}$

Castelo Branco

58059-900 - J oao Pessoa, PB - Brasil

Universidade Federal do Rio Grande do Norte, Centro de Ciências Sociais Aplicadas, Departamento de Ciências Contábeis.

Av. Senador Salgado Filho. S/N - Campus Universitário

Lagoa Nova

59076-000 - Natal, RN - Brasil

Universidade Federal de Sergipe, Centro de Educação de Ciências Humanas.

Av. Marechal Rondon s/ n Departamento de Educação sala 05

Rosa Elze

49000-000 - Sao Cristovao, SE - Brasil 